Multi-silicon ridge nanofabrication by repeated edge lithography

This article has been downloaded from IOPscience. Please scroll down to see the full text article.

2009 Nanotechnology 20315305

(http://iopscience.iop.org/0957-4484/20/31/315305)

The Table of Contents and more related content is available

Download details:

IP Address: 130.89.19.74

The article was downloaded on 14/07/2009 at 06:58

Please note that terms and conditions apply. 


\title{
Multi-silicon ridge nanofabrication by repeated edge lithography
}

\author{
Yiping Zhao ${ }^{1,2}$, Erwin Berenschot ${ }^{1}$, Henri Jansen ${ }^{1}$, Niels Tas $^{1}$, \\ Jurriaan Huskens ${ }^{2}$ and Miko Elwenspoek ${ }^{1,3}$ \\ ${ }^{1}$ Transducers Science and Technology, MESA+ Institute for Nanotechnology, \\ University of Twente, Enschede, The Netherlands \\ ${ }^{2}$ Molecular Nanofabrication, MESA + Institute for Nanotechnology, University of Twente, \\ Enschede, The Netherlands \\ ${ }^{3}$ FRIAS, Albert-Ludwigs University, Albertstr. 19, 79104, Freiburg, Germany \\ E-mail: y.zhao@ewi.utwente.nl
}

Received 25 February 2009, in final form 15 May 2009

Published 13 July 2009

Online at stacks.iop.org/Nano/20/315305

\begin{abstract}
We present a multi-Si nanoridge fabrication scheme and its application in nanoimprint lithography (NIL). Triple Si nanoridges approximately $120 \mathrm{~nm}$ high and $40 \mathrm{~nm}$ wide separated by $40 \mathrm{~nm}$ spacing are fabricated and successfully applied as a stamp in nanoimprint lithography. The fabrication scheme, using a full-wet etching procedure in combination with repeated edge lithography, consists of hot $\mathrm{H}_{3} \mathrm{PO}_{4}$ acid $\mathrm{SiN}_{x}$ retraction etching, 20\% KOH Si etching, 50\% $\mathrm{HF}$ $\mathrm{SiN}_{x}$ retraction etching and LOCal Oxidation of Silicon (LOCOS). Si nanoridges with smooth vertical sidewalls are fabricated by using $\mathrm{Si}\langle 110\rangle$ substrates and $\mathrm{KOH}$ etching. The presented technology utilizes a conventional photolithography technique, and the fabrication of multi-Si nanoridges on a full wafer scale has been demonstrated.
\end{abstract}

\section{Introduction}

Beam writing techniques, such as electron beam lithography (EBL) and focused ion beam lithography (FIB), have become the conventional and standard means of nanofabrication. To reduce the high cost and low throughput of nanofabrication using beam writing techniques, the fabrication of nano-structures employing unconventional methods has been an attractive research topic in nanotechnology [1]. Researchers have explored the possibilities of integration of micro-machining technologies, for example conventional photolithography, chemical vapor deposition of materials and micro-machining etching methods, into nanofabrication. Amongst all the unconventional methods, edge lithography is widely used and has proven to be a competent means of nanofabrication in combination with micro-machining technologies [2]. In edge lithography, the edges of the original pattern become the features of the final pattern.

Developed in a similar way to edge lithography, the spacer patterning technique (SPT) generally comprises: (1) sacrificial structures with vertical sidewalls patterned by photolithography and directional etching; (2) conformal deposition of another layer; (3) maskless directional etching of this layer; and (4) final selective etching of the sacrificial layer [3]. Several publications have demonstrated the fabrication of spacer-like structures employing similar working principles to SPT. Choi et al demonstrated the fabrication of nanoscale phosphosilicate glass (PSG) complementary metal oxide semiconductor (CMOS) by conformal deposition of PSG over an SiGe block pattern defined by photolithography, reactive ion etching of this PSG and removal of the SiGe sacrificial pattern [4]. Degroote used a SPT in combination with resist based patterning to define a Si-fin with a critical dimension below $20 \mathrm{~nm}$ [5]. Based on SPT, multi-SPT was developed by repeating a series of conformal deposition and anisotropic etching steps; it was shown to have potential in nanoelectronics applications $[6,7]$.

The multi-spacer patterns can also be created by a so-called planar edge defined alternate layer (PEDAL) process $[8,9]$. The PEDAL process consists of: (1) fabrication of trench-like structures with vertical sidewalls; (2) alternating deposition of materials upon the trench-like structure, e.g. silicon nitride and polysilicon; (3) substrate planarization by a spin-coated polymer; (4) etch-back of the polymer, silicon nitride and polysilicon by RIE etching; and finally (5) selective polysilicon etching to obtain spacers made of silicon nitride. Hussain et al employed a similar process flow to fabricate a template with Si nanowires for nanoimprint applications [10]. 


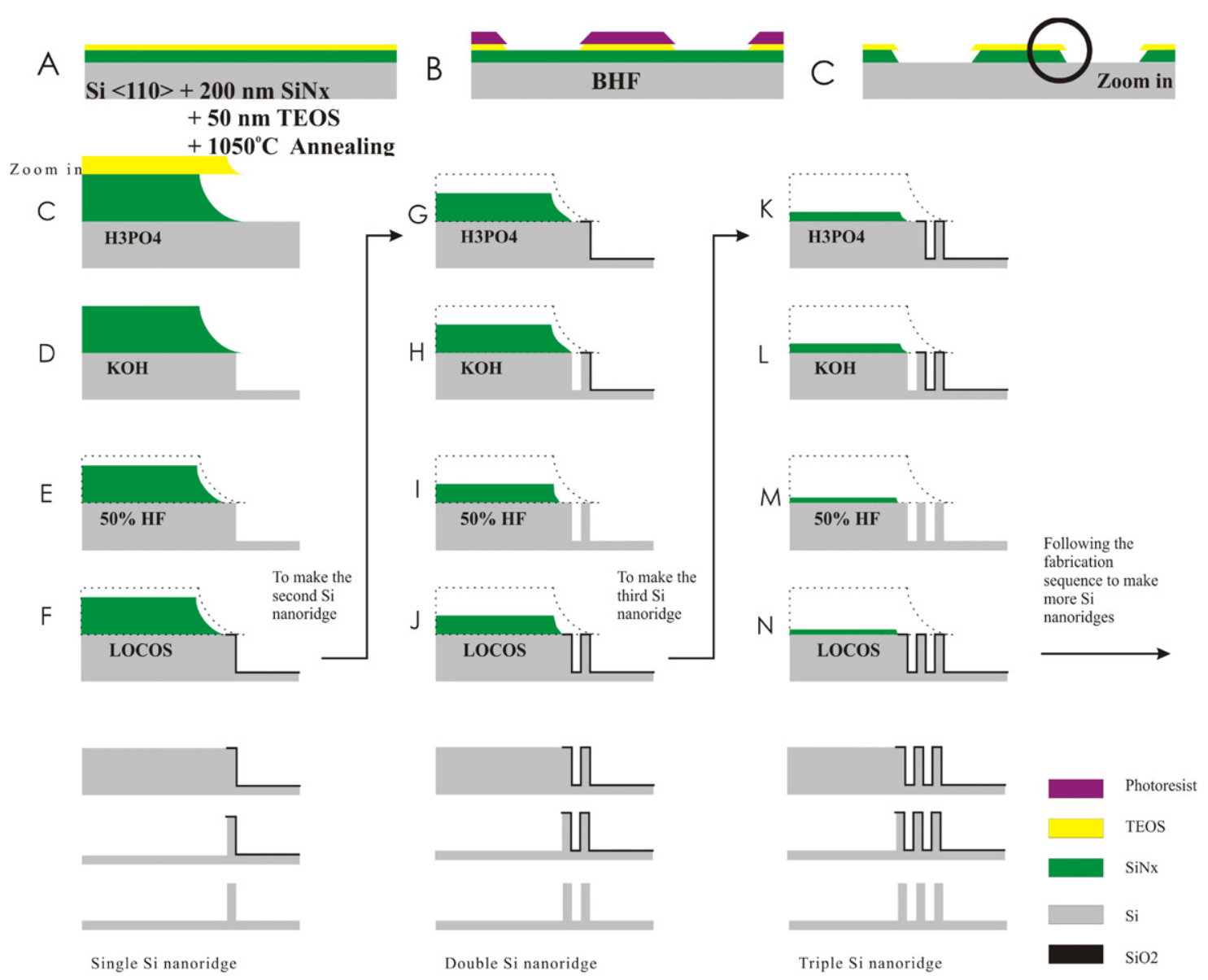

Figure 1. Multi-Si nanoridge fabrication scheme: (A)-(C) substrate preparation, grating pattern definition by photolithography and transfer into the top layers; (D) Si etching using 20\% KOH; (E) $\mathrm{SiN}_{x}$ retraction etching using 50\% HF; (F) LOCOS; (G)-(J) and (K)-(M) repeated edge lithography consisting of $\mathrm{SiN}_{x}$ retraction etching by hot $\mathrm{H}_{3} \mathrm{PO}_{4}$ acid, Si etching using $20 \% \mathrm{KOH}, \mathrm{SiN}_{x}$ retraction etching by $50 \% \mathrm{HF}$ and LOCOS. The fabrication sequence can be stopped by $\mathrm{SiN}_{x}$ total removal using hot $\mathrm{H}_{3} \mathrm{PO}_{4}$ acid, Si etching in $20 \% \mathrm{KOH}$ and final removal of $\mathrm{SiO}_{2}$ in $50 \% \mathrm{HF}$.

(This figure is in colour only in the electronic version)

Generally, the critical dimensions of the spacers fabricated by either SPT or PEDAL are defined by the conformal layer deposition. The initial pattern with vertical sidewalls determines the verticality of the spacers. Both smoothness of the initial pattern sidewalls and selective dry etching influence the smoothness and the shape of the spacer sidewalls. In a previous publication, we introduced a related but different technique - the fabrication of monocrystalline Si nanoridges by using a full-wet etch procedure including local oxidation of silicon (LOCOS) and an adapted edge lithography technique on top of conventional photolithography [2]. Here, we present the fabrication of multi-monocrystalline Si nanoridges using repeated edge lithography, which consists of sequentially performed $\mathrm{SiN}_{x}$ retraction etching in hot $\mathrm{H}_{3} \mathrm{PO}_{4}$ acid, $\mathrm{Si}$ etching in $\mathrm{KOH}, \mathrm{SiN}_{x}$ retraction etching in $50 \% \mathrm{HF}$ and LOCOS.

\section{Fabrication}

The fabrication scheme for multi-Si nanoridges is shown in figure 1: (A) $100 \mathrm{~mm}$, double side polished, p-type $\mathrm{Si}\langle 110\rangle$ substrates are used. The substrate is prepared with $200 \mathrm{~nm}$ low pressure vapor deposition (LPCVD) silicon-rich nitride $\left(\mathrm{SiN}_{x}\right)$ and $50 \mathrm{~nm}$ LPCVD tetraethylorthosilicate (TEOS) annealed in a furnace with a $\mathrm{N}_{2}$ atmosphere at $1050{ }^{\circ} \mathrm{C}$ for $1 \mathrm{~h}$. (B) The substrate is patterned by conventional photolithography using a resist mask (Olin 907-12) containing $4 \mu \mathrm{m}$ gratings covering the whole wafer surface. The substrate is treated in UV/ozone for $300 \mathrm{~s}$ to increase the hydrophilicity of the photoresist to improve TEOS wet etching. Then the TEOS is patterned by buffered $\mathrm{HF}\left(\mathrm{NH}_{4} \mathrm{~F}: \mathrm{HF}=1: 7\right)$ for $45 \mathrm{~s}$. Since the $\mathrm{SiN}_{x}$ surface shows hydrophilic behavior, like TEOS, about $10 \%$ over-etch is performed here to ensure complete pattern transfer. A dummy wafer with only a TEOS layer is used to test the etch rate. The completion of etching can be observed when the wafer surface turns from hydrophilic to hydrophobic. The etch rate of TEOS annealed at $1050{ }^{\circ} \mathrm{C}$ in buffered HF is approximately $80 \mathrm{~nm} \mathrm{~min}^{-1}$. (C) After stripping the photoresist in $100 \% \mathrm{HNO}_{3}$ for $20 \mathrm{~min}$, the $\mathrm{SiN}_{x}$ is patterned in $85 \% \mathrm{H}_{3} \mathrm{PO}_{4}$ heated up to $180{ }^{\circ} \mathrm{C}$ (referred to as hot $\mathrm{H}_{3} \mathrm{PO}_{4}$ acid in the remainder of the paper) using TEOS as the mask for $55 \mathrm{~min}$. The completion of etching can be observed when water runs along the patterned surface, since 


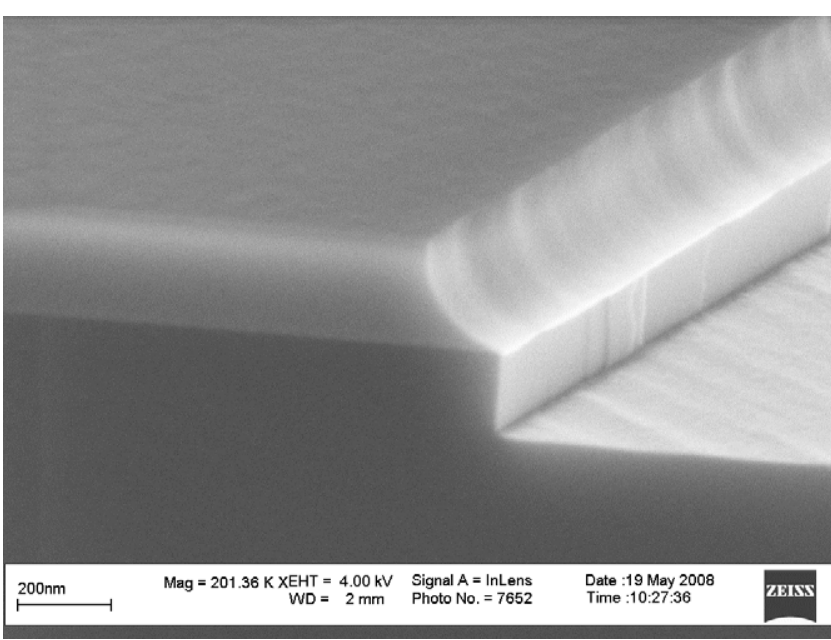

Figure 2. SEM image showing the etch result after step (D) of figure 1: Si etching in $20 \% \mathrm{KOH}$ for $5 \mathrm{~min}$.

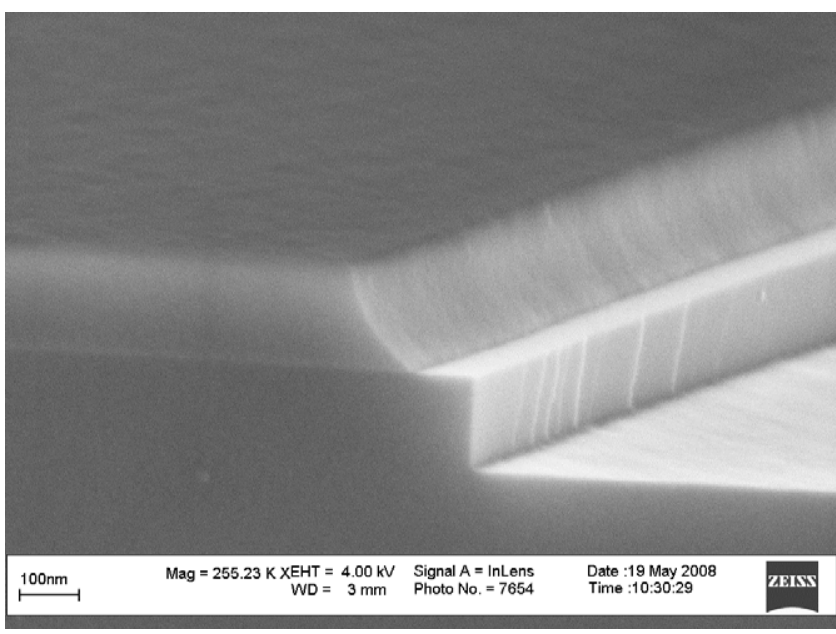

Figure 3. SEM image showing the result after step (E) of figure 1: $\mathrm{SiN}_{x}$ etching in $50 \% \mathrm{HF}$ for $25 \mathrm{~min}$.

the $\mathrm{Si}$ surface shows hydrophobic characteristics. The etch rate of $1050{ }^{\circ} \mathrm{C}$ annealed $\mathrm{SiN}_{x}$ and TEOS in hot $\mathrm{H}_{3} \mathrm{PO}_{4}$ acid is $3.9 \mathrm{~nm} \mathrm{~min}^{-1}$ and $0.29 \mathrm{~nm} \mathrm{~min}^{-1}$, respectively [11]. The $\mathrm{SiN}_{x}$ etching is carried out with about $10 \%$ over-etch to ensure complete pattern transfer. (D) Before Si etching, TEOS is stripped in $1 \% \mathrm{HF}$ for $20 \mathrm{~min}$. Anisotropic Si etching is performed in $20 \% \mathrm{KOH}$ used at room temperature (referred to as $20 \% \mathrm{KOH}$ in the remainder of the paper) for $5 \mathrm{~min}$ and followed by RCA-2 cleaning (a mixture of $\mathrm{HCl}: \mathrm{H}_{2} \mathrm{O}_{2}: \mathrm{H}_{2} \mathrm{O}$ of $5: 1: 1$ at $80^{\circ} \mathrm{C}$ ) for $10-15 \mathrm{~min}$ to remove contaminants harmful to the oxidation furnace in step F. The etch rate of $\mathrm{Si}\langle 110\rangle$ in $20 \% \mathrm{KOH}$ solution is $25 \mathrm{~nm} \mathrm{~min}{ }^{-1}$. (E) Then $\mathrm{SiN}_{x}$ retraction etching is carried out in $50 \% \mathrm{HF}$ for $25 \mathrm{~min}$ to obtain an opening on the Si surface. The etch rate of $\mathrm{SiN}_{x}$ in $50 \% \mathrm{HF}$ dropped from $2.7 \mathrm{~nm} \mathrm{~min}^{-1}$ before annealing to $1.7 \mathrm{~nm} \mathrm{~min}^{-1}$ after annealing at $1050{ }^{\circ} \mathrm{C}$. (F) Subsequently the exposed $\mathrm{Si}$ part is dry oxidized at $950{ }^{\circ} \mathrm{C}$ for 15 min using $\mathrm{SiN}_{x}$ as the mask (the so-called LOCOS process). (G) $\mathrm{SiN}_{x}$ retraction etching is performed in hot $\mathrm{H}_{3} \mathrm{PO}_{4}$ acid for 8 min to make an

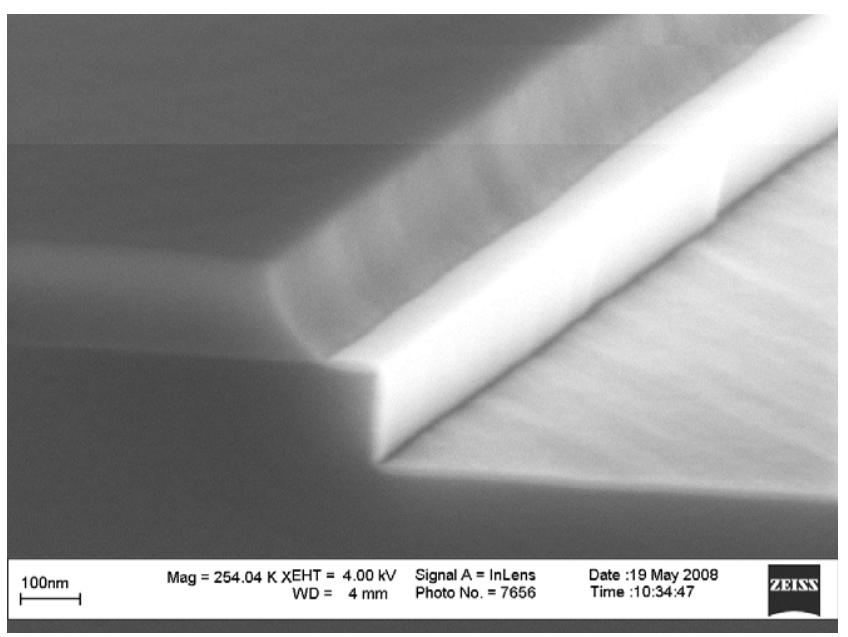

Figure 4. SEM image showing the result after step (F) of figure 1: LOCOS at $950{ }^{\circ} \mathrm{C}$ for $15 \mathrm{~min}$.

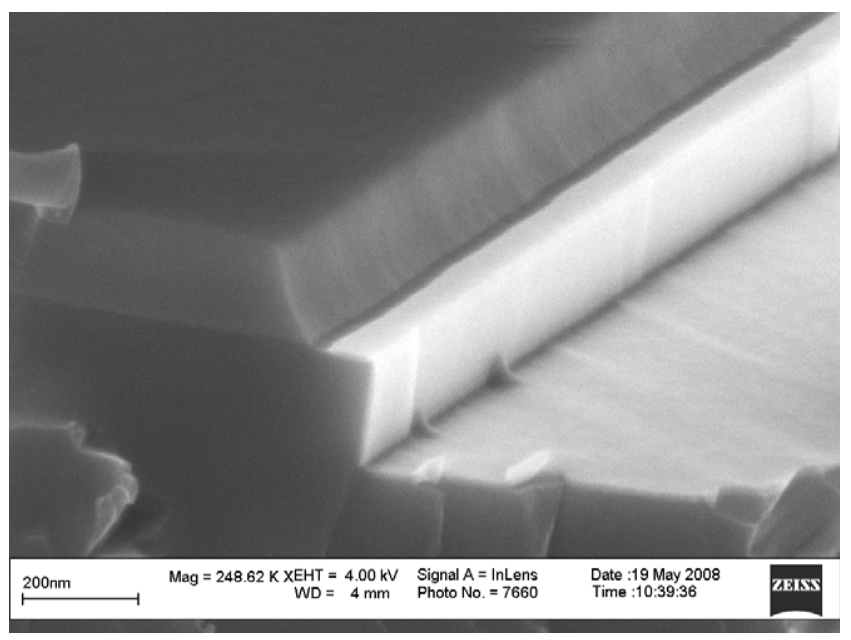

Figure 5. SEM image showing the result after step (G) of figure 1: $\mathrm{SiN}_{x}$ etching in hot $\mathrm{H}_{3} \mathrm{PO}_{4}$ acid for 8 min.

opening in the Si surface. (H) Si etching in $20 \% \mathrm{KOH}$ for 10 min. Figures 2-6 show the fabrication results in accordance with steps (D)-(H).

This edge lithography scheme, which consists of hot $\mathrm{H}_{3} \mathrm{PO}_{4}$ acid $\mathrm{SiN}_{x}$ retraction etching $(\mathrm{G}, \mathrm{K}), 20 \% \mathrm{KOH} \mathrm{Si}$ etching (D, H, L), 50\% $\mathrm{HF} \mathrm{SiN}_{x}$ retraction etching (E, I, $\mathrm{M})$ and $\operatorname{LOCOS}(\mathrm{F}, \mathrm{J}, \mathrm{N})$, is repeated to fabricate multi$\mathrm{Si}$ nanoridges. By iterating the repeated edge lithography steps results in the second fabricated Si nanoridge illustrated in figures 7 and 8. By terminating the fabrication scheme, for example after step $(\mathrm{F}),(\mathrm{J})$ or $(\mathrm{N})$, single, double or triple $\mathrm{Si}$ nanoridges can be obtained by complete removal of $\mathrm{SiN}_{x}$ in hot $\mathrm{H}_{3} \mathrm{PO}_{4}$ acid, Si etching in $20 \% \mathrm{KOH}$ and then complete removal of $\mathrm{SiO}_{2}$ in $50 \%$ HF. Stopped at step (N), figures 9 and 10 show examples of triple $\mathrm{Si}$ nanoridges by complete removal of $\mathrm{SiN}_{x}$ in hot $\mathrm{H}_{3} \mathrm{PO}_{4}$ acid, Si etching in $20 \% \mathrm{KOH}$ for $5 \mathrm{~min}$ and complete $\mathrm{SiO}_{2}$ removal in $50 \%$ HF. 


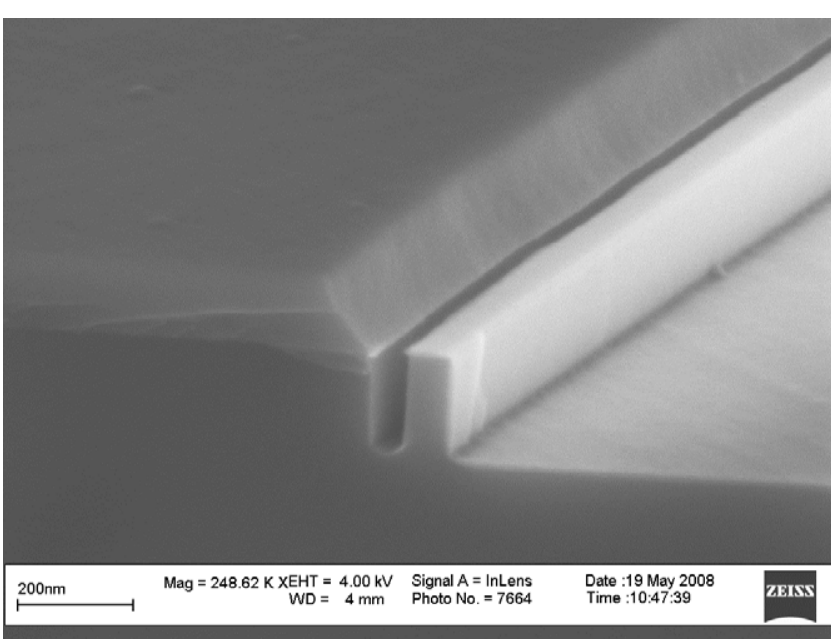

Figure 6. SEM image showing the result after step $(\mathrm{H})$ of figure 1: the first $\mathrm{Si}$ ridge is finished by anisotropic etching of $\mathrm{Si}$ in $20 \% \mathrm{KOH}$ for $10 \mathrm{~min}$

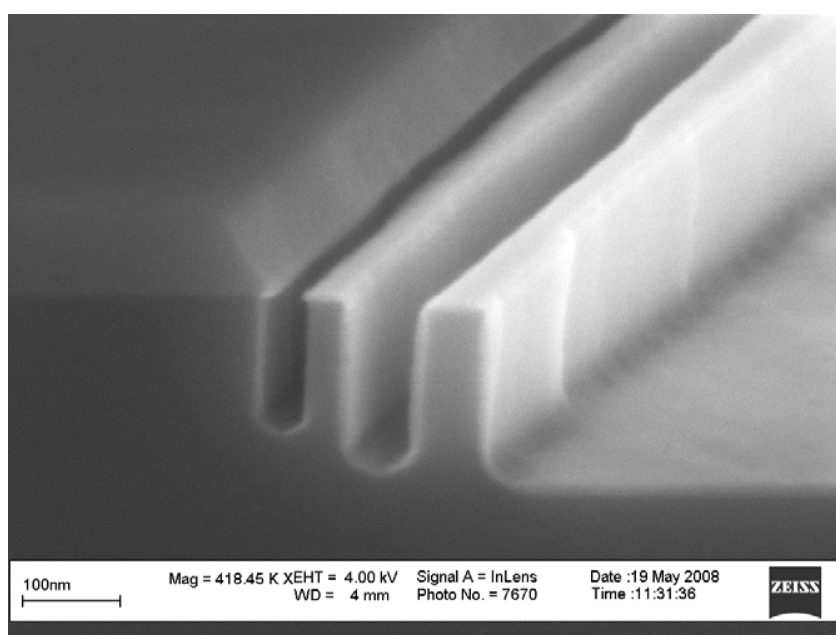

Figure 7. Continuation of Si nanoridge fabrication after figure 6 by repeating 50\% $\mathrm{HF} \mathrm{SiN}_{x}$ retraction etching for $25 \mathrm{~min}$, LOCOS at $950{ }^{\circ} \mathrm{C}$ for $15 \mathrm{~min}$, hot $\mathrm{H}_{3} \mathrm{PO}_{4}$ acid $\mathrm{SiN}_{x}$ retraction etching for 8 min and $20 \% \mathrm{KOH} \mathrm{Si}$ etching for $10 \mathrm{~min}$.

\section{Discussion}

\subsection{Substrate preparation and layer patterning}

To illustrate the feasibility of the multi-Si nanoridge fabrication scheme, we chose to deposit $200 \mathrm{~nm} \operatorname{SiN}_{x}$ and then $50 \mathrm{~nm}$ TEOS. The $1050^{\circ} \mathrm{C}$ annealing step is introduced to increase the etch selectivity of $\mathrm{SiN}_{x}$ to TEOS in hot $\mathrm{H}_{3} \mathrm{PO}_{4}$ acid from 1.4 (4.2 to $2.9 \mathrm{~nm} \mathrm{~min}^{-1}$ ) to 15 (3.9 to $0.29 \mathrm{~nm} \mathrm{~min}^{-1}$ ) [11]. Therefore, $50 \mathrm{~nm}$ TEOS is sufficient for pattern transfer into $200 \mathrm{~nm} \mathrm{SiN}_{x}$ in $52 \mathrm{~min}$. Normally $10 \%$ over-etch is performed to ensure complete etching. As shown in figure $2, \operatorname{SiN}_{x}$ displays an isotropically etched profile after etching in hot $\mathrm{H}_{3} \mathrm{PO}_{4}$ acid using TEOS as the mask.

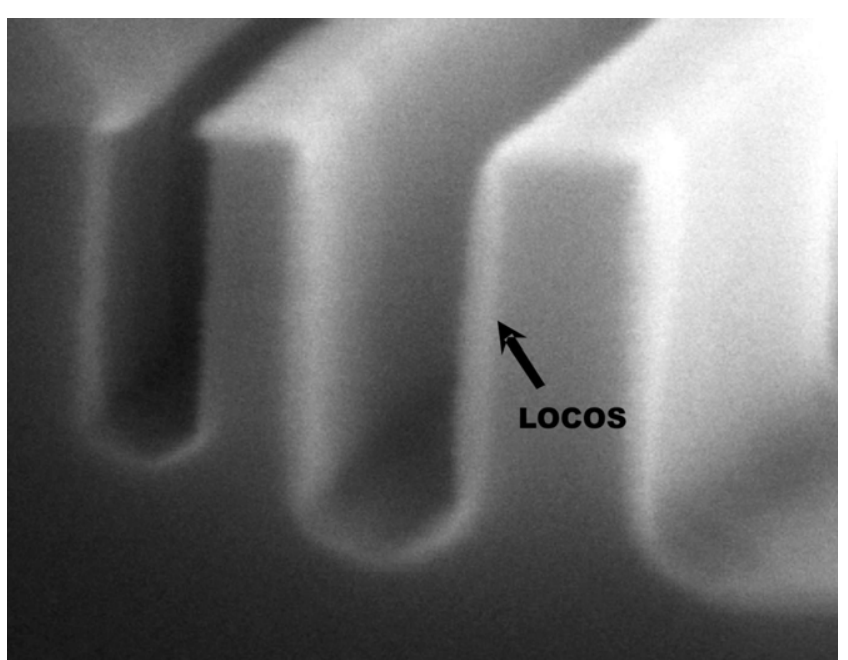

Figure 8. Magnification of figure 7 showing the non-uniform LOCOS inside the narrow trench.

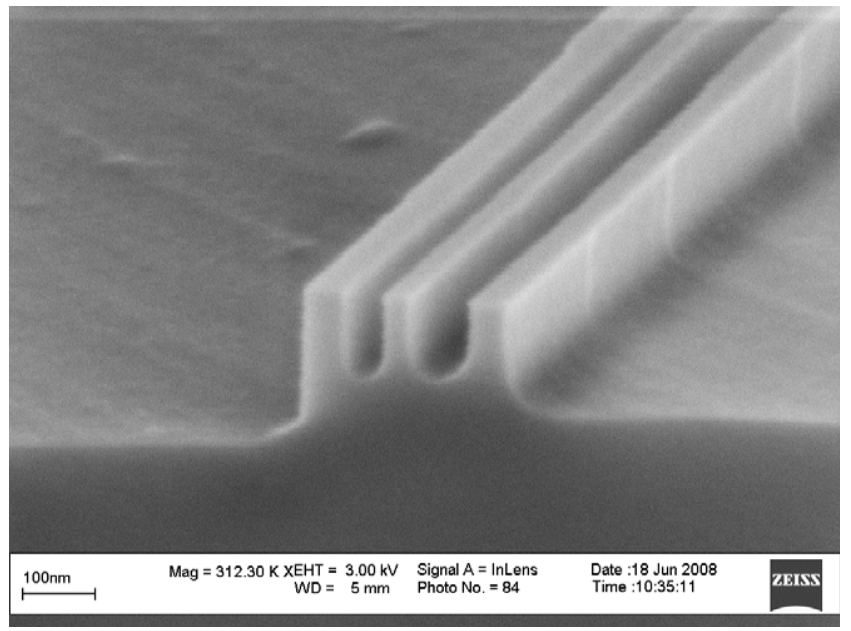

Figure 9. SEM image of triple Si nanoridges after complete removal of $\mathrm{SiN}_{x}, 20 \% \mathrm{KOH}$ etching and final removal of $\mathrm{SiO}_{2}$ in $50 \% \mathrm{HF}$.

\subsection{Si etching in $20 \% \mathrm{KOH}$ at room temperature (step D, $\mathrm{H}$,} L)

In figure 2, the vertical smooth $\mathrm{Si}$ sidewalls are achieved by $20 \% \mathrm{KOH}$ etching of $\mathrm{Si}\langle 110\rangle$ substrate, which automatically stops etching at $\mathrm{Si}\langle 111\rangle$ planes. For the purpose of this fabrication scheme, $20 \% \mathrm{KOH}$ is used instead of other standard wet chemicals for Si etching, which include OPD 4262, 5\% tetramethylammonium hydroxide (TMAH) used at $70^{\circ} \mathrm{C}$ and $25 \% \mathrm{KOH}$ used at $75^{\circ} \mathrm{C}$. Table 1 lists the etch rates of $\langle 110\rangle \mathrm{Si}$ and selectivities between $\mathrm{Si}\langle 111\rangle$ and $\mathrm{Si}\langle 110\rangle$ planes in these wet chemicals. The etch rates of $\mathrm{Si}\langle 110\rangle$ in 5\% TMAH used at $70{ }^{\circ} \mathrm{C}$ and $25 \% \mathrm{KOH}$ used at $75^{\circ} \mathrm{C}$ are too fast to be useful. Although the slow etch rate of OPD 4262 is favorable, the etch selectivity between the $\mathrm{Si}\langle 111\rangle$ and $\langle 110\rangle$ planes makes the etching of $\mathrm{Si}\langle 111\rangle$ planes non-negligible while making $\mathrm{Si}$ nanoridges 100-200 nm deep and a few tens of nanometers wide. Therefore the use of OPD 4262 in this scheme can lead to reduced control of the lateral dimensions of multi-Si 
Table 1. Etch rates of $\mathrm{Si}\langle 110\rangle$ planes and selectivity between $\mathrm{Si}\langle 110\rangle$ and $\langle 111\rangle$ planes in different etch solutions.

\begin{tabular}{lllll}
\hline & $\begin{array}{l}\mathrm{OPD} 4262 @ 20^{\circ} \mathrm{C} \\
\left.(\mathrm{nm} \mathrm{min})^{-1}\right)\end{array}$ & $\begin{array}{l}5 \% \mathrm{TMAH} @ 70{ }^{\circ} \mathrm{C} \\
\left.(\mathrm{nm} \mathrm{min})^{-1}\right)\end{array}$ & $\begin{array}{l}20 \% \mathrm{KOH} @ 20{ }^{\circ} \mathrm{C} \\
\left.(\mathrm{nm} \mathrm{min})^{-1}\right)\end{array}$ & $\begin{array}{l}25 \% \mathrm{KOH} @ 75{ }^{\circ} \mathrm{C} \\
\left(\mathrm{nm} \mathrm{min}^{-1}\right)\end{array}$ \\
\hline$\langle 110\rangle$ & 3.5 & 750 & 25 & 1800 \\
Selectivity $\langle 111\rangle:\langle 110\rangle$ & $1: 5$ & $1: 100$ & $1: 400[12]$ & $1: 400$ \\
\hline
\end{tabular}

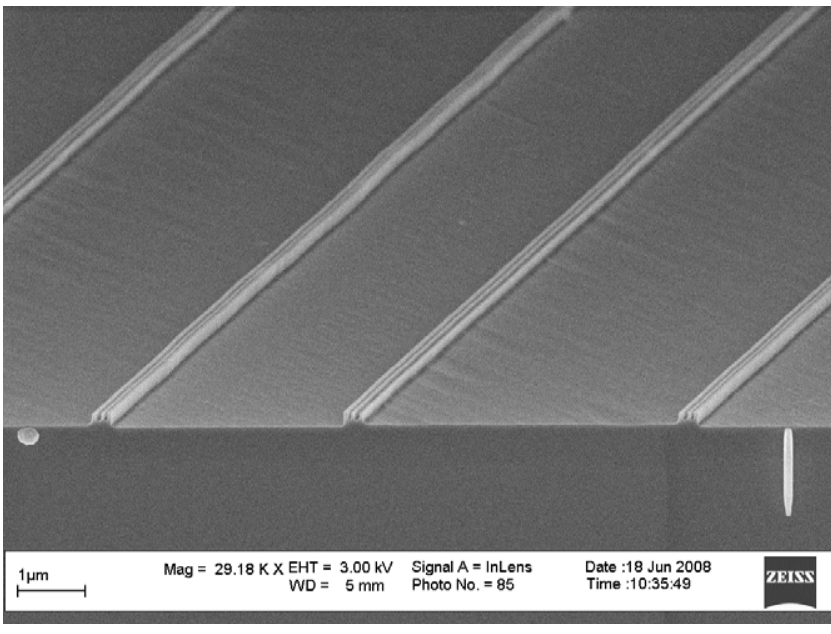

Figure 10. SEM image of an overview of groups of triple Si nanoridges.

nanoridges, and consequently making the control of spacing dimension more difficult. Therefore, $20 \% \mathrm{KOH}$ is selected, considering the relatively low etch rate on $\mathrm{Si}\langle 110\rangle$ planes and high selectivity between $\mathrm{Si}\langle 111\rangle$ and $\langle 110\rangle$ planes [12]. Moreover, the effect of line edge roughness brought by the use of conventional photolithography is avoided by self-alignment to $\mathrm{Si}\langle 111\rangle$ planes in $\mathrm{KOH}$ etching [13].

To obtain a relatively even level of the $\mathrm{Si}$ surface surrounding the $\mathrm{Si}$ nanoridges, the first $\mathrm{KOH}$ etching shown in figure 2 is executed for 5 min while the following $20 \% \mathrm{KOH}$ Si etching shown in figures 6 and 7 is performed for $10 \mathrm{~min}$. It is estimated that the large difference in the trench aspect ratio is the reason for the difference in etching time. In figures 6 and 7 , the trench aspect ratio (depth to width) is approximately $3: 1$ $(120 \mathrm{~nm}: 40 \mathrm{~nm})$, while the trench aspect ratio is about 0.03:1 $(120 \mathrm{~nm}: 4000 \mathrm{~nm})$ in figure 2. In this specific case, to obtain an even trench depth, etching the nano-sized opening takes roughly twice as long as the time needed for the $4 \mu \mathrm{m}$ opening. This effect can be called KOH lag and closely resembles RIE lag [14]. At present, we assume the reason behind the $\mathrm{KOH}$ lag is the depletion of active species into deep and narrow trenches.

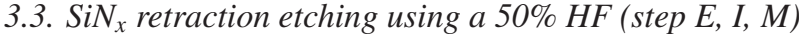

After $\mathrm{Si}$ patterning in $20 \% \mathrm{KOH}$ and RCA-2 cleaning, $\mathrm{SiN}_{x}$ is etched in both lateral and vertical directions using $50 \% \mathrm{HF}$ for $25 \mathrm{~min}$ to receive an approximately $40 \mathrm{~nm}$ opening on the $\mathrm{Si}$ surface, as shown in figure 3 . As the $\mathrm{Si}$ edge is exposed to the etchant, $50 \% \mathrm{HF}$ is used instead of hot $\mathrm{H}_{3} \mathrm{PO}_{4}$ to avoid $\mathrm{Si}$ surface attack [2].

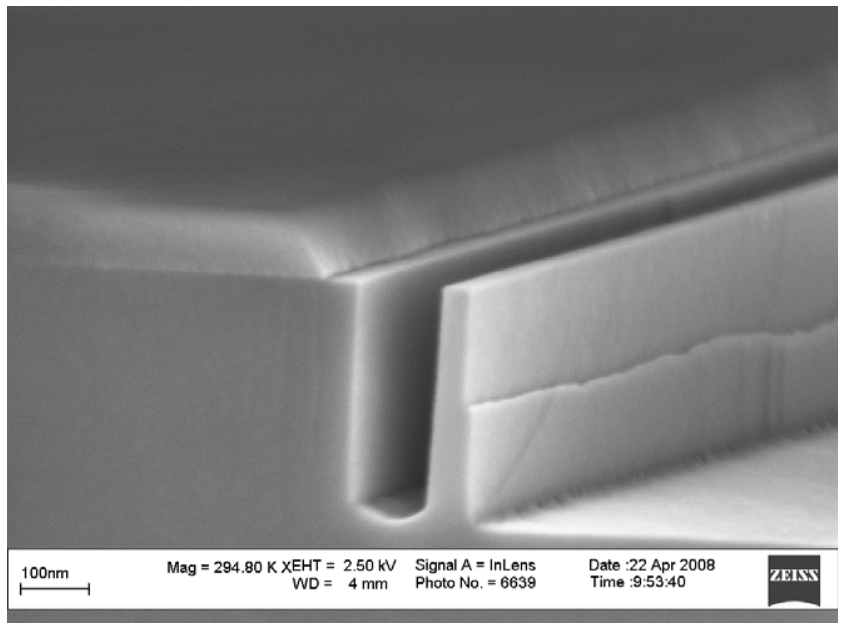

Figure 11. SEM image of a Si nanoridge with a cleavage at its side.

\section{4. $\operatorname{LOCOS}($ step $F, \mathrm{~J}, \mathrm{~N})$}

The LOCOS step is executed to form a thermal $\mathrm{SiO}_{2}$ layer on the fabricated $\mathrm{Si}$ edges to protect them from being deteriorated in the following hot $\mathrm{H}_{3} \mathrm{PO}_{4}$ acid $\mathrm{SiN}_{x}$ retraction etching and $20 \% \mathrm{KOH} \mathrm{Si}$ etching steps. Except for the purpose of serving as the protective layer, this $\mathrm{SiO}_{2}$ layer influences the dimensions of the fabricated $\mathrm{Si}$ ridges and spacing between them. Since Si is consumed during oxidation, the LOCOS step leads to shrinkage in Si nanoridge height and width and widening of the spacing. Therefore we tried decreasing the oxidation time to minimize the influence of LOCOS. A thickness of $2 \mathrm{~nm} \mathrm{SiO} 2$ proved to be sufficient to withstand $20 \% \mathrm{KOH}$ etching $\mathrm{Si}\langle 110\rangle$ for $400 \mathrm{~nm}$ at room temperature [12]. Figure 11 shows a Si ridge with a cleavage at the side. In this case, the protective $\mathrm{SiO}_{2}$ was obtained by 5 min LOCOS (about $10 \mathrm{~nm} \mathrm{SiO}_{2}$ obtained), which proved to be insufficient due to the non-uniform $\mathrm{SiO}_{2}$ thickness at shaped Si surfaces as discussed by Marcus et al [15]. The drawings shown in figure 12 illustrate the shaped Si surface after LOCOS for 5 min followed by etching in hot $\mathrm{H}_{3} \mathrm{PO}_{4}$ acid for $15 \mathrm{~min}$ [16]. Since the $\mathrm{SiO}_{2}$ at the top corner is thinner, it can first be etched away during $\mathrm{SiN}_{x}$ retraction etching in hot $\mathrm{H}_{3} \mathrm{PO}_{4}$ acid. The cleavage is then made during the next $20 \%$ $\mathrm{KOH}$ Si etching step as a result of opening at the protective $\mathrm{SiO}_{2}$ layer. It is reported that the non-uniform $\mathrm{SiO}_{2}$ thickness can be suppressed by: (1) increasing the oxidation temperature, (2) adding $\mathrm{NH}_{3}$ gas during dry oxidation; or (3) decreasing the oxidation rate by inert gas addition [15, 17, 18]. All of these solutions are based on the fact that the oxide stress is reduced by viscous relaxation. Concerning this multi-Si nanoridge fabrication scheme, the LOCOS temperature cannot 


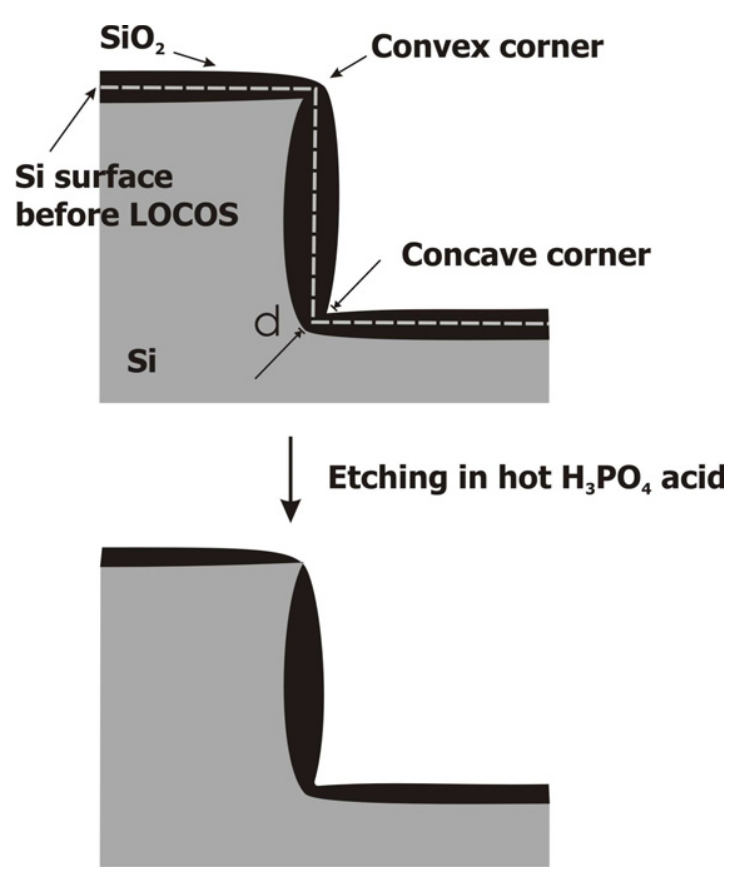

Figure 12. Illustrations of oxidation of a shaped Si surface. Top: oxidation of shaped Si surface [16]. Bottom: $\mathrm{SiO}_{2}$ etched in hot $\mathrm{H}_{3} \mathrm{PO}_{4}$ acid.

go beyond $1100^{\circ} \mathrm{C}$ so as to keep the intrinsic characteristics of $\mathrm{SiN}_{x}$ [19]. Besides improving the uniformity of oxide growth, the selectivity between the $\mathrm{SiN}_{x}$ and $\mathrm{SiO}_{2}$ layers might be increased as found by Vos [20]. The improvement of the $\mathrm{SiO}_{2}$ growth or $\mathrm{SiN}_{x}$ selectivity needs further investigation but this is beyond the scope of this paper.

The result of LOCOS inside a narrow trench after dry oxidation can be observed in figure 8 with the help of the illustration in figure 12. Clearly, the thickness of the grown oxide layer depends on the position along the wall. At the convex and concave corners it is less than on the other positions as observed by Marcus [15]. Moreover, the thickness depends on the orientation of the underlying silicon surface [21]. Depletion of the oxidizing agent seems to be unlikely because both the narrow $(40 \mathrm{~nm})$ as well as the wide open trenches $(4 \mu \mathrm{m})$ have an almost identical oxide layer at their surface. Further research is needed to fully understand the oxidation behavior in narrow high aspect ratio trenches.

\subsection{SiN ${ }_{x}$ retraction etching using hot $\mathrm{H}_{3} \mathrm{PO}_{4}$ acid (steps $\mathrm{G}, \mathrm{K}$ )}

After LOCOS, hot $\mathrm{H}_{3} \mathrm{PO}_{4}$ acid is used for $\mathrm{SiN}_{x}$ retraction etching taking advantage of the selectivity between $\mathrm{SiN}_{x}$ and $\mathrm{SiO}_{2}$ (3.9 to $0.25 \mathrm{~nm} \mathrm{~min}^{-1}$ ). An opening of $20 \mathrm{~nm}$ on the Si surface is obtained by etching $\mathrm{SiN}_{x}$ in hot $\mathrm{H}_{3} \mathrm{PO}_{4}$ acid for $8 \mathrm{~min}$, as shown in figure 5. Because the $\mathrm{SiN}_{x}$ etch rate is $3.9 \mathrm{~nm} \mathrm{~min}{ }^{-1}$, we should have observed $31 \mathrm{~nm}$ of retraction. However, $\mathrm{SiN}_{x}$ is partly oxidized during the LOCOS [22]. Due to this oxide, we have a delay of approximately $2 \mathrm{~min}$ before $\mathrm{SiN}_{x}$ starts etching. Finally, we find that the etching of $\operatorname{SiN}_{x}$ in hot $\mathrm{H}_{3} \mathrm{PO}_{4}$ acid plays an important role in influencing the uniformity of etching over the whole wafer. Therefore, a stirrer is used to maintain a uniform temperature within the heated acid.

\subsection{The determination of multi-Si nanoridge dimensions}

As can be concluded from the previous discussions, the height of the $\mathrm{Si}$ nanoridges is predominantly determined by $20 \% \mathrm{KOH}$ Si etching while the width of each Si nanoridge and the opening between the $\mathrm{Si}$ nanoridges are largely determined by $50 \% \mathrm{HF} \mathrm{SiN}_{x}$ retraction etching and hot $\mathrm{H}_{3} \mathrm{PO}_{4}$ acid $\mathrm{SiN}_{x}$ retraction etching, respectively. Moreover, the LOCOS step influences the dimensions of the multi$\mathrm{Si}$ nanoridges by reducing the width and height of the $\mathrm{Si}$ nanoridges and consequently widening the spacing between them. In other words, the width and height of the fabricated $\mathrm{Si}$ nanoridges are decreased in the subsequent fabrication steps due to the consumption of $\mathrm{Si}$ in LOCOS. Also the proposed multi-Si ridge nanofabrication scheme is performed with uniform results on a full $100 \mathrm{~mm}$ wafer scale. By knowing these factors, each $\mathrm{Si}$ nanoridge and spacing can be tuned according to specific requirements after calculation and careful experimental handling. Furthermore, the $\mathrm{Si}$ substrate is prepared with $200 \mathrm{~nm} \mathrm{SiN}_{x}$ and $50 \mathrm{~nm}$ TEOS to show the feasibility of our fabrication scheme. The substrate can be prepared with different $\mathrm{SiN}_{x}$ layer thicknesses considering the dimensions and number of $\mathrm{Si}$ nanoridges required. Accordingly, the TEOS layer thickness can also be tuned as needed. Since the multi-Si nanoridge process steps can be well controlled, we assume that the fabrication of $\mathrm{Si}$ nanoridges down to $10 \mathrm{~nm}$ is attainable, as we have already demonstrated the successful wafer-scale fabrication of single Si nanoridges down to $10 \mathrm{~nm}$ by edge lithography in our previous publication [2].

\section{Application in nanoimprint lithography}

The fabricated triple $\mathrm{Si}$ nanoridge sample, as shown in figures 9 and 10, is used in thermal nanoimprinting [23]. Before imprinting, the wafer template is cleaned in Piranha $\left(\mathrm{H}_{2} \mathrm{SO}_{4}: \mathrm{H}_{2} \mathrm{O}_{2}=3: 1\right.$, around $\left.100^{\circ} \mathrm{C}\right)$ for $30 \mathrm{~min}$, rinsed with deionized (DI) water and blown dry with $\mathrm{N}_{2}$. Then, a monolayer of $1 \mathrm{H}, 1 \mathrm{H}, 2 \mathrm{H}, 2 \mathrm{H}$-perfluorodecyltrichlorosilane is deposited from the gas phase under vacuum condition in a desiccator. This layer acts as the anti-adhesion layer on the mold to facilitate demolding. The imprint process is performed on a wafer coated with PMMA (MW $38 \mathrm{kDa}, 4 \mathrm{wt} \%$ as to receive $200 \mathrm{~nm}$ layer thickness at $3000 \mathrm{rpm}$ spin rate) using an Obducat thermal nanoimprint machine. The imprint is carried out at $180^{\circ} \mathrm{C}$ and 40 bar for $10 \mathrm{~min}$ and the demold temperature is $90{ }^{\circ} \mathrm{C}$. The imprint result is shown in figure 13 . We observed polymer filling problems inside Si narrow trenches of the imprint sample, as can be seen in the image. We did not try to solve the problem since polymer filling is a typical issue in thermal nanoimprinting and goes beyond the focus of this paper.

\section{Conclusions}

A multi-Si ridge nanofabrication scheme has been successfully used in producing multi-Si nanoridges. The use of $20 \% \mathrm{KOH}$ and a $\mathrm{Si}\langle 110\rangle$ substrate promises to obtain smooth and vertical 


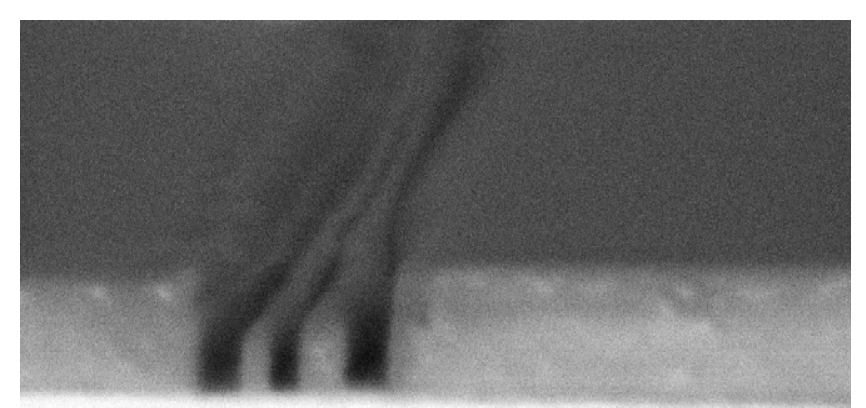

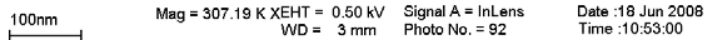

Figure 13. SEM image of thermal nanoimprint in PMMA (38 kDa) using the triple Si ridge template as shown in figure 9.

Si sidewalls, which automatically stops at the $\mathrm{Si}\langle 111\rangle$ planes. Different from spacer patterning technology, the incorporation of LOCOS improves the dimension and shape of the silicon ridges. Without relying on the resolution of beam writing technologies, the width of an individual $\mathrm{Si}$ nanoridge and spacing can be well controlled by $\mathrm{SiN}_{x}$ retraction etching in $50 \% \mathrm{HF}$ and hot $\mathrm{H}_{3} \mathrm{PO}_{4}$ acid, respectively. We have demonstrated ridges $120 \mathrm{~nm}$ high, $40 \mathrm{~nm}$ wide and $40 \mathrm{~nm}$ apart but are confident of reaching sub-10 nm resolution without complicating the process scheme. We can fabricate these multi-Si nanoridges with uniform dimensions within the $100 \mathrm{~mm}$ wafer scale by using photolithography and the full-wet etching scheme. Multi-Si nanoridges with specific dimensions can be produced by modifying the fabrication parameters as required, such as the layer thickness of $\mathrm{SiN}_{x}$ and TEOS, etching time of $\mathrm{SiN}_{x}$ and $\mathrm{Si}$ and oxidation time.

\section{Acknowledgments}

Mark Smithers is acknowledged for his help in taking the SEM pictures. The project is financed by Nanoned through Strategic Research Orientation (SRO) program Nanofabrication at MESA+ Institute for Nanotechnology at the University of Twente.

\section{References}

[1] Gates B D, Xu Q, Stewart M, Ryan D, Willson C G and Whitesides G M 2005 New approaches to nanofabrication: molding, printing, and other techniques Chem. Rev. 105 1171-96

[2] Zhao Y, Berenschot E, Jansen H, Tas N, Huskens J and Elwenspoek M 2009 Sub-10 nm silicon ridge nanofabrication by advanced edge lithography for NIL applications Microelectron. Eng. 86 832-5

[3] Hunter W R, Holloway T C, Chatterjee P K and Tasch A F Jr 1981 A new edge-defined approach for submicrometer MOSFET fabrication IEEE Electron Device Lett. 2 4-6
[4] Choi Y-K, King T-J and Hu C 2002 A spacer patterning technology for nanoscale CMOS IEEE Trans. Electron Devices 49 436-41

[5] Degroote B et al 2007 Spacer defined FinFET: active area patterning of sub-20 nm fins with high density Microelectron. Eng. 84 609-18

[6] Cerofolini G F, Arena G, Camalleri C M, Galati C, Reina S, Renna L and Mascolo D 2005 A hybrid approach to nanoelectronics Nanotechnology 161040

[7] Cerofolini G F, Amato P and Romano E 2008 The multi-spacer patterning technique: a non-lithographic technique for terascale integration Semicond. Sci. Technol. 23075020

[8] Sonkusale S R, Amsinck C J, Nackashi D P, Di Spigna N H, Barlage D, Johnson M and Franzon P D 2005 Fabrication of wafer scale, aligned sub-25 $\mathrm{nm}$ nanowire and nanowire templates using planar edge defined alternate layer process Physica E 28 107-14

[9] Sonkusale S R, Di Spigna N H and Franzon P D 2007 Uniformity analysis of wafer scale sub-25 nm wide nanowire array nanoimprint mold fabricated by PEDAL process Microelectron. Eng. 84 1523-7

[10] Hussain M M, Labelle E, Sassman B, Gebara G, Lanee S, Moumen N and Larson L 2007 Deposition thickness based high-throughput nano-imprint template Microelectron. Eng. $84594-8$

[11] Bruinink C M, Burresi M, de Boer M J, Segerink F B, Jansen H V, Berenschot E, Reinhoudt D N, Huskens J and Kuipers L 2008 Nanoimprint lithography for nanophotonics in silicon Nano Lett. 8 2872-7

[12] Namatsu H, Nagase M, Kurihara K, Iwadate K, Furuta T and Murase K 1995 Fabrication of sub-10-nm silicon lines with minimum fluctuation J. Vac. Sci. Technol. B 13 1473-6

[13] Kendall D L 1975 On etching very narrow grooves in silicon Appl. Phys. Lett. 26 195-8

[14] Jansen H V, Boer M J d, Unnikrishnan S, Louwerse M C and Elwenspoek M C 2009 Black silicon method X: a review on high speed and selective plasma etching of silicon with profile control: an in-depth comparison between Bosch and cryostat DRIE processes as a roadmap to next generation equipment J. Micromech. Microeng. 19033001

[15] Marcus R B and Sheng T T 1982 The oxidation of shaped silicon surfaces J. Electrochem. Soc. 129 1278-82

[16] Minh P N, Ono T and Esashi M 1999 Nonuniform silicon oxidation and application for the fabrication of aperture for near-field scanning optical microscopy Appl. Phys. Lett. 75 4076-8

[17] Imai K and Yamabe K 1990 Nonplanar silicon oxidation in dry $\mathrm{O}_{2}+\mathrm{NF}_{3}$ Appl. Phys. Lett. 56 280-2

[18] Yamabe K and Imai K 1987 Nonplanar oxidation and reduction of oxide leakage currents at silicon corners by rounding-off oxidation IEEE Trans. Electron Devices 34 1681-7

[19] Zhao Y, Berenschot E, Boer M d, Jansen H, Tas N, Huskens J and Elwenspoek M 2008 Fabrication of a silicon oxide stamp by edge lithography reinforced with silicon nitride for nanoimprint lithography J. Micromech. Microeng. 18064013

[20] Vos R, Lux M, Conard T, De Witte H, Mertens P, Heyns M and Hatcher Z 2000 Improved phosphoric acid mixtures for nitride strip Diffus. Defect Data B 76/77 43-6

[21] Lewis E A and Irene E A 1987 The effect of surface orientation on silicon oxidation kinetics J. Electrochem. Soc. 134 2332-9

[22] Fränz I and Langheinrich W 1971 Conversion of silicon nitride into silicon dioxide through the influence of oxygen Solid-State Electron. 14 499-505

[23] Guo L J 2007 Nanoimprint lithography: methods and material requirements $A d v$. Mater. $19495-513$ 